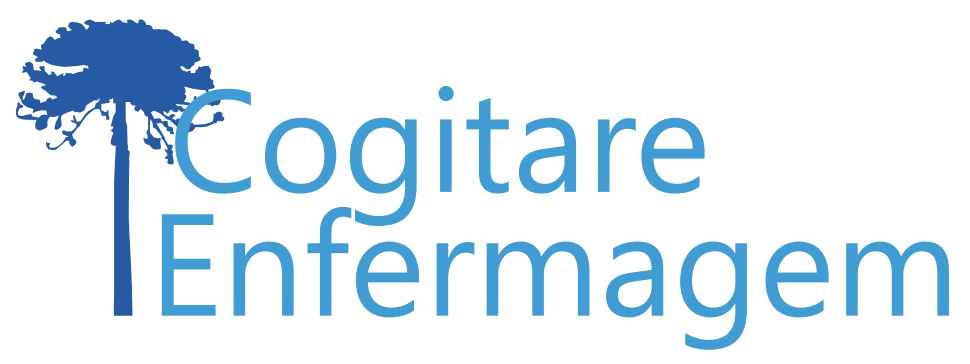

RELATO DE EXPERIÊNCIA

\title{
CRIAÇÃO E IMPLEMENTAÇÃO DE UM PERIÓDICO CIENTÍFICO NA ÁREA DE ENFERMAGEM E SAÚDE
}

\author{
Paloma de Souza Cavalcante Pissinati ${ }^{1}$ (i) \\ Raquel Grozd Costa ${ }^{2}$ (i) \\ Evelin Daiane Gabriel Pinhatti ${ }^{3}$ (i) \\ Renata Perfeito Ribeiro ${ }^{2}$ (1)
}

\begin{abstract}
RESUMO
Objetivo: relatar a experiência de criação e implementação de um periódico científico na área de enfermagem e saúde.

Método: relato de experiência da criação e implementação de um periódico científico na área de enfermagem e saúde, no norte do Paraná, Brasil, entre outubro de 2018 e setembro de 2019.

Discussão: ao delinear missão, política editorial e escopo do periódico, além da formação do Conselho Fundador e o regimento interno, normas, corpo editorial, implementação da versão eletrônica, no portal de periódicos da universidade, redes sociais e o lançamento em evento científico com participação da comunidade interna e externa à universidade, deixa-se explícita a seriedade e rigor necessários nesse processo.

Conclusão: a criação e implementação ocorreu de forma sistemática, levando em consideração padrões de qualidade. O relato contribui para que outros pesquisadores possam estruturar novos periódicos, ao retratar todas as etapas percorridas desde o planejamento até a publicação do primeiro volume.
\end{abstract}

DESCRITORES: Editoração; Publicação Periódica; Publicações de Divulgação Científica; Comunicação e Divulgação Científica; Enfermagem.

\section{CREACIÓN Y IMPLEMENTACIÓN DE UN PERIÓDICO CIENTÍFICO EN EL ÁREA DE ENFERMERÍA Y SALUD}

\section{RESUMEN:}

Objetivo: relatar la experiencia de creación e implementación de un periódico científico en el área de enfermería y salud. Método: relato de experiencia de la creación e implementación de un periódico científico en el área de enfermería y salud, en el norte de Paraná, Brasil, entre octubre de 2018 y septiembre de 2019. Discusión: al delinear la misión, política editorial y alcance del periódico, además de la formación del Consejo Fundador y el reglamento interno, las normas, el cuerpo editorial, implementación de la versión electrónica, en el portal de periódicos de la universidad, redes sociales y el lanzamiento en un evento científico con la participación de la comunidad interna y externa de la universidad, se explícita la seriedad y rigor necesarios en este proceso. Conclusión: la creación e implementación ocurrió de manera sistemática, teniendo en cuenta padrones de calidad. El relato contribuye a que otros investigadores puedan estructurar nuevos periódicos, al retratar todos los pasos dados desde la planificación hasta la publicación del primer volumen.

DESCRIPTORES: Edición; Publicación Periódica; Publicaciones de Divulgación Científica; Comunicación e Divulgación Científica; Enfermería. 
O desenvolvimento da ciência agregou valores substanciais aos sistemas de saúde ao longo dos anos, uma vez que permitiu, continuamente, aprimorar a prática profissional a partir de resultados das pesquisas ${ }^{(1)}$. Dentre os fatores que contribuíram para essa evolução, bem como para a visibilidade das diferentes profissões e a formação de um corpo teórico robusto, está a criação de periódicos científicos.

No que se refere ao início das publicações científicas, apesar da existência de pensamentos filosóficos registrados desde a mitologia grega, as revistas científicas desenvolveram-se mais recentemente, nos séculos XVII e XVIII, com crescimento expressivo desde então. A importância da divulgação científica está incorporada em todos os cenários acadêmicos e profissionais. Atualmente, o periódico deve buscar a qualidade de suas publicações para, assim, ampliar sua visibilidade e qualificação no ambiente editorial(2).

Nos últimos anos, tem-se observado uma expansão de cursos e programas de pós-graduação stricto sensu no Brasil, os quais são responsáveis por impulsionar o desenvolvimento da ciência, tecnologia e informação. Assim, a disponibilização de periódicos científicos de qualidade também pode contribuir para a divulgação de produções científicas robustas, com impactos diretos para a melhoria da prática profissional ${ }^{(3)}$.

Internacionalmente, tem-se adotado diferentes indicadores bibliométricos para avaliar a qualidade dos periódicos e das pesquisas publicadas, no que se refere ao seu impacto e ressonância no meio acadêmico(4). O primeiro e mais utilizado índice para ranquear instituições, periódicos e publicações foi o Fator de Impacto (FI), criado em 1975, tendo a partir de 2004 outros concorrentes como o SCImago Journal \& Country Rank (SJR) implantado pela Elsevier ${ }^{(5)}$.

No Brasil, dentre as estratégias utilizadas para a avaliação da qualidade da produção científica dos programas de pós-graduação, destaca-se a estratificação Qualis-Capes, que tem passado por uma reestruturação, ainda em avaliação nas áreas de conhecimento, com o objetivo de equilibrar a avaliação entre as áreas e alinhar os critérios à internacionalização(b).

A adoção de critérios de avaliação deve estar presente desde o delineamento inicial da proposta de um novo periódico. A equipe editorial também deve analisar os fatores dificultadores e as potencialidades de um novo meio de divulgação para a área. Portanto, a criação e implementação de um periódico científico voltado à área de enfermagem e saúde representa o produto de uma avaliação detalhada que, aliada à preocupação em atender aos indicadores de qualidade, reforça a possibilidade de alcançar o reconhecimento e visibilidade no meio acadêmico.

Diante do exposto, objetivou-se relatar a experiência de criação e implementação de um periódico científico na área de enfermagem e saúde.

\section{MÉTODO}

Trata-se de relato de experiência construído a partir da criação e implementação de um periódico científico na área de enfermagem e saúde. O estudo foi realizado no Departamento de Enfermagem da Universidade Estadual de Londrina, localizada no norte do estado do Paraná, no período de outubro de 2018 a setembro de 2019.

A criação do periódico seguiu as etapas sistematizadas desde a definição da missão e do corpo editorial, até a implementação da versão eletrônica, conforme detalhado a 
seguir.

Foram levantados os critérios utilizados por bases de dados nacionais e internacionais para avaliação de periódicos, a fim de garantir que o novo periódico fosse delineado em consonância com os padrões necessários para pleitear estas indexações. Optou-se por seguir os requisitos das bases de dados científicas Scientific Electronic Library Online (SCIELO) e Literatura Latino-Americana e do Caribe em Ciências da Saúde (LILACS).

No que se refere à periodicidade, determinou-se que o periódico teria um fluxo contínuo (rolling pass) de publicação, além de um corpo editorial e de consultores ad hoc nacionais e internacionais, com adoção de avaliação cega por pares (peer review).

A formação do Conselho Fundador, composto por docentes e pesquisadores da instituição de estudo e externos a esta, que atuavam em diferentes linhas de pesquisas e com experiência na área de editoração em outros periódicos científicos, constituiu-se um passo fundamental para alcançar um olhar ampliado na construção da missão e no delineamento do periódico. A partir de reuniões periódicas, foram definidos o regimento interno da revista, instruções aos autores, fluxo de recebimento e avaliação de artigos, a missão e o escopo, além da política e corpo editorial.

A proposta de implementação foi submetida à tramitação na universidade e, mediante aprovação junto à Pró-Reitoria de Pesquisa e Pós-Graduação, Centro de Ciências da Saúde e Departamento de Enfermagem, a revista foi vinculada ao Departamento de Enfermagem e ao Programa de Pós-Graduação em Enfermagem.

Com o apoio do Departamento de Design, definiu-se o layout, estilos de fontes e cartela de cores, bem como o template do formato Portable Document Format (PDF) dos artigos eletrônicos, tendo como premissa torná-lo atrativo, intuitivo e facilitar a leitura do conteúdo pelo usuário. Finalizada esta etapa, implementou-se a versão eletrônica, disponibilizada no portal de periódicos da Universidade, associada à divulgação das mídias sociais para maior visibilidade.

O lançamento do periódico ocorreu em um evento científico, organizado pelo corpo editorial e equipe de apoio, com mais de 120 participantes e transmissão ao vivo e acessos em território nacional e internacional, como a reprodução em tempo real em uma Universidade de Portugal.

No primeiro volume foram publicados um editorial e dez artigos científicos, sendo que todos os autores pertenciam a instituições de ensino externas à Universidade à qual o periódico está vinculado.

\section{DISCUSSÃO}

A criação de um novo periódico científico surge com o intuito de contribuir para a ampliação da comunicação e valorização da ciência, tendo desde o projeto inicial a preocupação em garantir o rigor e qualidade das publicações. Apesar do elevado número de periódicos científicos existentes em áreas específicas, observou-se a necessidade de disponibilizar um novo espaço de divulgação de estudos, não somente para a área de enfermagem, mas para outras vinculadas à saúde.

A busca pela indexação em bases de dados tem sido almejada por periódicos científicos da área de saúde e enfermagem para ampliar a visibilidade e alcançar a internacionalização. Contudo, para alcançar tais padrões, faz-se necessária a estruturação de recursos humanos e materiais, além da necessidade de que o periódico possua um tempo mínimo de criação, periodicidade e qualidade dos artigos publicados ${ }^{(7)}$. 
Dentre os critérios de indexação de periódicos, está o alcance de padrões de indicadores bibliométricos, os quais visam avaliar o impacto dos artigos científicos a partir do número de citações recebidas ${ }^{(8)}$. Atualmente, as métricas alternativas, como acesso por meio de mídias sociais, recomendaç̃es, compartilhamentos e downloads, também têm sido adotadas para mensurar a visibilidade do periódico na comunidade acadêmica( ${ }^{(9)}$.

A preocupação em formar um corpo editorial qualificado integra as ações de boas práticas de editoração científica adotadas pelo periódico, com vistas a garantir a transparência e o rigor em todo processo de avaliação dos artigos. Aliado a isso, a adoção do sistema de publicação em fluxo contínuo (rolling pass) permite maior agilidade na divulgação dos artigos aprovados, uma vez que não há necessidade de aguardar a finalização de um novo volume, pois são disponibilizados assim que finalizada a diagramação(10).

A estratégia de utilização de mídias sociais por periódicos científicos tem sido fortemente adotada nacional e internacionalmente, como ferramenta para ampliar o alcance e o impacto frente à comunidade em geral. Estes meios são utilizados como fontes para obtenção de dados altimétricos, em complementariedade aos indicadores bibliométricos ${ }^{(7,11)}$.

Ressalta-se que os editores podem encontrar dificuldades frente à criação de um novo periódico, tais como a formação de um uma equipe editorial com interesse e disponibilidade para participar de todas as etapas de estruturação, e justificar à instituição e comunidade externa a necessidade de criação de um novo periódico, sobretudo diante do atual cenário de limitações financeiras.

A fim de superar estes dificultadores, buscou-se articulações internas e externas, junto a outras universidades nacionais e internacionais, para fortalecer e solidificar o corpo editorial. O apoio institucional e o aceite de editores com expertise na área de editoração científica foram fundamentais para viabilizar a implementação do periódico.

A busca de consultorias externas com editores que possuíam experiência na editoração de periódicos científicos da área de enfermagem e saúde também constituiu-se uma importante ferramenta para decisões como a adoção do fluxo contínuo (rolling pass) a partir do primeiro volume. A partir dessa parceria, evidenciou-se que, mesmo com todas as dificuldades enfrentadas, "ser editor" traz satisfação e permite ao profissional contribuir com o avanço científico de sua área.

\section{CONCLUSÃO}

A criação e implementação de um novo periódico científico na área de enfermagem e saúde ocorreu de forma sistemática, com evidente preocupação com padrões de qualidade. A adoção de ferramentas para o monitoramento contínuo dos indicadores bibliométricos e altimetria poderão contribuir para a maior visibilidade e solidificação no meio científico.

As vivências que permearam esse processo reforçam a importância do planejamento, da busca por parcerias e estratégias para superar as dificuldades enfrentadas na implementação.

O presente relato contribui para a estruturação de novos periódicos científicos, ao retratar as etapas percorridas, desde o planejamento inicial até a publicação do primeiro volume do periódico. Além disso, estimula-se aos profissionais da área de saúde e enfermagem, que buscam o aprimoramento e a carreira acadêmica em programas de pósgraduaçã̃o, que não limitem sua contribuição à comunidade científica somente à submissão de manuscritos, mas possam avançar na atuação enquanto pareceristas e editores de periódicos. 
1. Chambers DA, Feero WG, Khouri MJ. Convergence of implementation science, precision medicine, and the learning health care system: a new model for biomedical research. JAMA [Internet]. 2016 [acesso em 19 out 2019]; 315(18). Disponível em: http://dx.doi.org/10.1001/jama.2016.3867.

2. Lüscher TF. The future of scientific publishing. Eurolntervention [Internet]. 2019 [acesso em 16 maio 2020]; 15. Disponível em: https://doi.org/10.4244/EIJV15I2A28.

3. Scochi CGS, Munari DB, Gelbcke FL, Ferreira MA. Desafios e estratégias dos programas de pósgraduação em enfermagem para a difusão da produção científica em periódicos internacionais. Esc Anna Nery [Internet]. 2014 [acesso em 19 out 2019]; 18(1). Disponível em: http://dx.doi.org/10.5935/14148145.20140001.

4. Bornmann L, Marx W. The journal impact factor and alternative metrics. EMBO Rep [Internet]. 2016 [acesso em 23 nov 2019]; 17. Disponível em: http://dx.doi.org/10.15252/embr.201642823.

5. Nassi-Calò L. Métricas de avaliação em ciência: estado atual e perspectivas. Rev LatinoAm Enfermagem [Internet]. 2017 [acesso em 23 nov 2019]; 25. Disponível em: http://dx.doi. org/10.1590/1518-8345.0000.2865.

6. Coordenação de Aperfeiçoamento de Pessoal de Nível Superior. CAPES melhora ferramentas de avaliação da pós-graduação [Internet]. 2019 [acesso em 23 nov 2019]. Disponível em: http://www.capes. gov.br/36-noticias/9730-capes-melhora-ferramentas-de-avaliacao-da-pos-graduacao.

7. Avena MJ, Barbosa DA. Periódicos brasileiros de enfermagem: fortalezas, fragilidades e desafios. Rev Bras Enferm [Internet]. 2018 [acesso em 23 nov 2019]; 71(5). Disponível em: http://dx.doi. org/10.1590/0034-7167-2017-0828.

8. Belter CW. Bibliometric indicators: opportunities and limits. J Med Libr Assoc [Internet]. 2015 [acesso em 23 nov 2019]; 103(4). Disponível em: http://dx.doi.org/10.3163/1536-5050.103.4.014.

9. Ball R. Scientific profiling instead of bibliometrics: key performance indicators of the future. Infozine [Internet]. 2016 [acesso em 23 nov 2019]; (spe1). Disponível em: https://doi.org/10.3929/ ethz-a-010744972.

10. Marziale MHP. Desafios na gestão editorial de periódicos científicos. Rev Baiana Enferm [Internet]. 2017 [acesso em 23 nov 2019]; 31(3). Disponível em: https://doi.org/10.18471/rbe.v31i3.24028.

11. Voytek B. Social media, open science, and data science are inextricably Linked. Neuron [Internet]. 2017 [acesso em 16 maio 2020]; 96(6). Disponível em: https://doi.org/10.1016/j.neuron.2017.11.015. 
COMO REFERENCIAR ESTE ARTIGO:

Pissinati P de SC, Costa RG, Pinhatti EDG, Ribeiro RP. Criação e implementação de um periódico científico na área de enfermagem e saúde. Cogitare enferm. [Internet]. 2021 [acesso em "colocar data de acesso, dia, mês abreviado e ano"]; 26. Disponível em: http://dx.doi.org/10.5380/ce.v26i0.70457.

Recebido em: 30/11/2019

Aprovado em:16/08/2020

Editora associada: Luciana Puchalski Kalinke

\section{Autor Correspondente:}

Paloma de Souza Cavalcante Pissinati

Universidade Estadual de Londrina - Londrina, PR, Brasil

E-mail: cavalcanteps7@gmail.com

\section{Contribuição dos autores:}

Contribuiçães substanciais para a concepção ou desenho do estudo; ou a aquisição, análise ou interpretação de dados do estudo - PSCP, RPR

Elaboração e revisão crítica do conteúdo intelectual do estudo - PSCP, RGC, EDGP

Aprovação da versão final do estudo a ser publicado - RPR

Copyright () 2021 Este é um artigo em acesso aberto distribuído nos termos da Licença Creative Commons Atribuição, que permite o uso irrestrito, a distribuição e reprodução em qualquer meio desde que o artigo original seja devidamente citado. 